\title{
Os Nordestes de Freyre e Furtado'
}

\author{
José Henrique Artigas de Godoy
}

\begin{abstract}
Resumo
O artigo busca relacionar duas interpretações clássicas do pensamento social e econômico do Brasil e do Nordeste formuladas por Gilberto Freyre e Celso Furtado. Freyre foi um dos responsáveis pela definição da categoria Nordeste a partir de referenciais não apenas naturais, mas também sociais, econômicos, políticos e culturais. Furtado, por sua vez, foi o mais destacado intelectual a defender políticas públicas regionais para o Nordeste, realçando as características particulares que condicionavam a subordinação política, social, econômica e cultural da região em relação ao Centro-Sul do país. Com trajetórias de vida bastante diferentes, Freyre e Furtado expõem retratos díspares do Brasil e do Nordeste. Escreveram sob conjunturas e referenciais analíticos diversos, não obstante apresentam abordagens inovadoras que se aproximam na busca totalizante de uma explicação verdadeira do Brasil, do Nordeste e do nordestino.
\end{abstract}

Palavras-chave: Gilberto Freyre. Celso Furtado. Nordeste.

\section{Introdução: cosmopolitismo e regionalismo}

Este artigo busca relacionar distintas interpretaçôes que fizeram escola no pensamento social e econômico do Brasil e do Nordeste em dois momentos históricos marcados por mudanças estruturais, os anos 20 e 30 do século XX, influenciados pelo regionalismo e pelo getulismo, e os 50 e 60 , quando são defendidas novas estratégias de desenvolvimento e integração nacional. Nestes diferentes momentos-chave dos processos de modernização, Gilberto Freyre e Celso Furtado expuseram retratos díspares do Brasil e do Nordeste. Os

I Este artigo é uma versão modificada de paper apresentado à $34^{a}$ Reunião Anual da Associação Nacional de Pós-Graduação em Ciências Sociais (ANPOCS), de 2010. O texto original também envolvia a trajetória e a obra de Joaquim Nabuco. Agradeço comentários e críticas recebidos quando da apresentação, especialmente vindos de José Murilo de Carvalho, Nisia Trindade Lima, Ricardo Benzaquem de Araújo, Luis Werneck Vianna e Rubem Barbosa Filho.

2 Doutor em Ciência Política pela Universidade de São Paulo, São Paulo, Brasil, e professor do Departamento de Ciências Sociais e do Programa de Pós-Graduação em Sociologia da Universidade Federal da Paraiba (UFPB), João Pessoa, Brasil. É autor de artigos publicados nas revistas CSOnline (UFJF, 2010), Cadernos Imbondeiro (2010) e Política E Trabalho (Impresso) (UFPB, 2009).E-mail: jhartigasgodoy@gmail.com. 
autores apresentam abordagens inovadoras e inaugurais na história do pensamento brasileiro. Cada qual escrevendo sob uma conjuntura e um referencial analítico particulares, aproximam-se na busca totalizante de uma explicação verdadeira do Brasil, do Nordeste e do nordestino.

Freyre era pernambucano do Recife, Furtado, paraibano da sertaneja Pombal. A produção intelectual de ambos foi vastíssima. Refletiram sobre o Nordeste sem jamais renderem-se ao provincianismo localista. Foram cosmopolitas.

Freyre teve uma formação com fortes referências anglo-saxãs. Desde muito cedo vivenciou a tradição protestante e teve uma trajetória educacional em instituições bilíngues, estudou no Colégio Americano Gilreath e depois no liceu batista norte-americano do Recife. As influências culturais anglo-saxãs foram um estímulo aos estudos superiores, feitos nos Estados Unidos - nas universidades de Baylor, no Texas, e Columbia, em Nova York - e continuados na Inglaterra, em Oxford. Após graduar-se, defendeu o Masters of Arts em Columbia, com um trabalho escrito em inglês, embora já versando sobre a temática que o celebrizou: a vida social no Brasil em meados do século XIX. $\mathrm{Na}$ Inglaterra, Freyre aprofundou seus estudos sobre sexualidade na formação patriarcal brasileira. Mais tarde, ao voltar para o exterior como professor visitante de Stanford, o autor teve a oportunidade de visitar os estados do sul dos Estados Unidos, o que foi importante para verificar as particularidades históricas do modelo escravista brasileiro. No exterior escreveu Casa-grande e senzala, parcialmente rascunhado em Nova York, sob o estímulo de Oliveira Lima. Após 1951 se alinhou ao salazarismo e rodou o mundo procurando aproximar em torno do lusotropicalismo os povos colonizados pelos portugueses. Mais tarde, as tendências favoráveis aos norte-americanos levaram o Instituto Joaquim Nabuco, idealizado por Freyre, a se tornar um instrumento da "Aliança para o progresso", seguindo o discurso panamericanista de Nabuco, embora sob uma circunstância distinta, de explícito imperialismo. As relaçôes de intimidade com Castelo Branco reforçaram suas posiçóes em favor do alinhamento irrestrito aos interesses dos Estados Unidos. Em 1967 foi dignificado com o título de Cavaleiro Comandante do Império Britânico, atribuído pela rainha Elizabeth. Destacando as influências aristocráticas e anglo-saxâs, Maria Lúcia Pallares Burke classifica Freyre como um vitoriano nos trópicos. 
Cosmopolita, Celso Furtado também viveu em diversas cidades do mundo. Graduou-se no Rio de Janeiro, doutorou-se na Universidade de Paris/ Sorbonne e mudou-se para o Chile com a fundação da CEPAL. A partir daí passou a viajar com constância, passando por Argentina, Costa Rica, Venezuela, Equador, Peru e Estados Unidos. Sua obra mais famosa, Formação Econômica do Brasil, foi escrita no King's College, da Universidade de Cambridge. Após o Golpe de 1964, com os direitos cassados, foi convidado para lecionar em Harvard, Yale e Columbia, mas voltou ao Chile para dar aulas no ILPES. Mais tarde foi professor e pesquisador das mais importantes universidades do mundo, como Cambridge, Columbia, Yale e Washington. Faleceu após 20 anos de docência na Sorbonne.

A experiência internacional e política permitiu a esses autores-chave do pensamento brasileiro construírem visóes originais sobre o Brasil. Olhando de dentro e de fora, de longe e de perto, com distanciamento, mas sem alienar a proximidade, a afetividade e os valores nativos expressos em suas trajetórias, Freyre e Furtado foram intérpretes do Brasil. Suas obras principais foram escritas no exterior, mas sempre com o olhar voltado para as particularidades culturais, políticas e econômicas do Brasil, comumente destacando os condicionantes regionais. Com enfoques diferentes, defenderam seus argumentos e valores tanto no campo intelectual quanto no político. Ocuparam postos importantes na política nacional e regional. A partir do acompanhamento da trajetória e de algumas obras desses autores ilustres, este artigo procura apresentar seus diagnósticos e suas prescriçôes para o enfrentamento dos problemas sociais, políticos e econômicos do Nordeste.

\section{A criação do Nordeste e dos nordestinos}

A categoria Nordeste foi associada, inicialmente, à região submetida às secas. Desde o final do século XIX, destaca-se um conjunto de identidades naturais da regiáo. As estiagens de 1877 a 1879 geraram o maior êxodo rural de até então. 300 mil pessoas morreram em função dos efeitos da seca. Meio milhão de nordestinos migrou. Destes, 200 mil cearenses. Estima-se que cerca de $4 \%$ da população brasileira à época tenha sofrido as consequências das estiagens, vivendo o que viria a ser conhecido como flagelo das secas (POMPONET, 2010, p. 2). Em meio ao desenvolvimento do polo da borracha na fronteira amazônica e ao estímulo à migração, mais de 250 mil 
nordestinos se deslocaram para a nova fronteira amazônica, fugindo do flagelo das secas (VILLA, 2000, p. 83).

Em 1877, ano em que teve início o mais longo período de estiagens do Nordeste no século XIX, o Imperador destacava que a prolongada falta de chuvas em algumas províncias do Norte teria acarretado "provaçóes inerentes a semelhante flagelo" (FALAS DO TRONO, 1977, p. 443). O imperador ainda voltaria ao tema defendendo a criaçáo de políticas públicas que minimizassem, no futuro, os efeitos "de tamanha calamidade" (FALAS DO TRONO, 1977, p. 446).

Pouco antes, em 1875, o cearense José de Alencar, em $O$ sertanejo, havia traçado um retrato da seca, da fome e da miséria do interior do Nordeste. Em $O s$ Sertôes, de Euclides da Cunha, reforçou a imagem de região abandonada, ao descrever a luta diária contra as agruras do meio, que exigiria do homem uma resistência característica em face do ambiente inóspito e do domínio do latifúndio.

Criado em 1909, o Instituto de Obras Contra as Secas (IOCS) referia-se à categoria geográfica Nordeste como o espaço onde se concentravam as áreas que sofriam com os efeitos das longas estiagens. Dez anos depois, o IOCS se tornou Instituto Federal (IFOCS), precursor do atual Departamento Nacional de Obras Contra as Secas (DNOCS), criado em 1945. Segundo Durval Muniz de Albuquerque Júnior, o Nordeste é filho das secas (ALBUQUERQUE JR, 2009).

Em 1918, último ano da gestão presidencial de Venceslau Brás, a ideia de D. Pedro II de transposição das águas do rio São Francisco foi transformada em projeto oficial. Naquele ano o governo federal gastou 2.326 contos de réis com obras na região. No governo seguinte, do paraibano Epitácio Pessoa, os investimentos no Nordeste chegaram ao ápice durante o período da I República, atingindo 145.947 contos de réis (POMPONET, 2010, p. 3). Logo após a posse, Epitácio propôs um conjunto de obras para o Nordeste, no sentido de preparar a regiáo para as secas:

Sabe-se hoje que no Nordeste há irregularidade, mas não faltam chuvas. Tudo está em poder armazenar as águas caídas nos meses chuvosos, para gastá-las na irrigação durante os meses de seca. Construídas as barragens para a formação de açudes e abertos os canais de irrigação, virá por si a colonização das terras por essa gente laboriosa, cuja coragem e resistência assombram os que não lhe conhecem as virtudes. (PESSOA, 2004). 
O antigo IOCS se transformou, na gestão Epitácio, em IFOCS, sob uma circunscrição administrativa de atuação que deu origem à primeira elaboração oficial da categoria geográfica e administrativa Nordeste.

Em paralelo às primeiras definiçôes geográficas e administrativas do Nordeste, pautadas por questôes naturais, surgiram vertentes intelectuais, artísticas e literárias que também auxiliaram na definição da categoria, procurando demarcar identidades socioculturais oriundas dos séculos de tradiçáo patriarcal e rural da regiáo. O movimento regionalista, liderado por Gilberto Freyre, foi o marco de criação de uma geração de intérpretes do Nordeste, a exemplo de José Lins do Rego, José Américo de Almeida, Vicente Rego Monteiro, Manuel Bandeira, Câmara Cascudo, Francisco Brennand e Cícero Dias. Seguindo vertente díspar, embora também focalizando as particularidades do Nordeste e do nordestino, pode-se destacar Raquel de Queiroz, Joáo Cabral de Melo Neto, Jorge Amado, Caribé, Dorival Caymmi, assim como Ariano Suassuna e Dias Gomes, intérpretes que tornaram a categoria Nordeste popular e reconhecida por um conjunto de valores, de formas de vida, de estilos musicais, estéticos, gastronômicos, com laços de identidade regional referenciados por um passado compartilhado que, de forma quase mítica, constrói seus personagens pela descrição dos tipos do cabra, do capanga, do jagunço, do coronel, do beato, do cangaceiro, do sertanejo, do matuto.

A definição desses tipos humanos como característicos da mitologia nordestina, associada à valorização de padróes tradicionais de vida e cultura próprios dessa área de influência, envolveu o regionalismo das décadas de 20 e 30 do século XX na definição daquilo que integrava e dava identidade àqueles habitantes da Bahia ao Maranhão, definidos como nordestinos. Forjava-se, assim, uma cultura nordestina. Ao lado de uma cultura nordestina haveria, então, uma economia nordestina, uma política nordestina, uma sociedade nordestina.

\section{Freyre e o regionalismo nordestino}

Em 1925, Gilberto Freyre foi responsável pela organizaçáo de uma publicaçáo em homenagem ao centenário do Diário de Pernambuco, reunindo textos sobre as tradiçóes regionais, o qual viria a ser publicado como o Livro do Nordeste, que serviria de embriáo ao movimento cultural irradiado a partir do Recife nos anos seguintes. Em 1926, Freyre abriu o I Congresso Brasileiro de Regionalismo. Em 1952, lançou um texto que supostamente teria circulado 
naquele encontro ocorrido no Recife e que viria a ser conhecido como $M a$ nifesto Regionalista. Nele o autor definia os princípios do movimento cultural e artístico criado a partir das articulaçóes do Congresso (BURKE, 2005, p. 233). Nesse encontro teria início o "Movimento Regionalista, Tradicionalista e, ao seu modo, Modernista do Recife". A ressalva "ao seu modo" indicava uma perspectiva particular, definida no intuito de distinguir o regionalismo do Recife do movimento paulista do grupo da Semana de 1922.

O regionalismo criticava os estrangeirismos, buscando valorizar as tradiçóes culturais do Nordeste. Seus adeptos denunciavam o "furor neófilo" dos dirigentes que imitavam a novidade estrangeira. No Manifesto é patente a crítica ao Império e à Corte "afrancesada ou anglicizada", assim como à República, "ianquizada".

Os regionalistas professavam que a civilizaçáo do açúcar havia contribuído para a originalidade brasileira náo apenas na doçura ou no tempero. Consideravam que nos decênios anteriores o nordestino vinha perdendo a tradição de criador ou recriador de valores para verter-se em uma populaçáa "quase parasitária” (FREYRE, 2009 [1952], p. 5).

A valorização das características tradicionais da cultura nordestina, antes que provinciana, tinha como sentido a afirmação da identidade nacional por meio de sua expressão regional. Segundo o Manifesto, a "maior injustiça que se pode fazer a um regionalismo como o nosso seria confundi-lo com separatismo ou bairrismo" (FREYRE, 2009 [1952], p. 3). O Manifesto propunha a "superação do estadualismo [...] para substituí-lo por um novo e flexível sistema em que as regióes, mais importantes que os estados, se completem e se integrem ativa e vigorosamente em uma verdadeira organizaçáo nacional" (FREYRE, 2009 [1952], p. 3).

Desde a volta do exterior para o Recife, ainda em 1923, sobressai o olhar retrospectivo e o apelo de Freyre à tradição. $\mathrm{O}$ autor denuncia a modernidade periférica, e no "confronto com o culto do novo, muitas de suas preferências se orientam para o antigo ou para o misterioso: igrejas, ruas sombreadas, escritores místicos, histórias de assombraçôes" (GIUCCI; LARRETA, 2007, p. 214-215). Antes que argumento exclusivamente retrógrado ou reacionário, seria um meio de propor uma via particular de desenvolvimento, de modernizaçáo. A ideia do regionalismo envolvia a busca de uma via de modernização 
que valorizasse o regional como forma de afirmação da identidade e não se rendesse aos ímpetos universalizantes, importados de realidades exógenas e que não expressariam os valores próprios da cultura nacional.

O maior patrimônio do país residiria na sua identidade cultural mestiça, fluida, flexível e, ao mesmo tempo, doce, amável, voluptuosa, quente. Por isso deveríamos preservá-la das influências degenerativas dos valores frios e exageradamente racionalistas das metrópoles modernas. Freyre se aproxima do modernismo ao afirmar uma versão cosmopolita que valoriza as particularidades da identidade brasileira, mas se distancia dos paulistas ao se voltar para a exaltação do passado, das raízes patriarcais da cultura do Nordeste.

Freyre procurava, na definição da identidade brasileira forjada nos trópicos, afirmar a originalidade cultural pelo viés da exaltação de princípios encantados, estéticos, eróticos, sentimentais, alheios aos limites burocráticos do racionalismo, do utilitarismo, do individualismo e da moral cristã burguesa. Defendia a possibilidade de construção de uma nova modernidade nos trópicos, partida de pressupostos morais construídos sob os séculos de colonialismo civilizador português.

A vantagem comparativa do Brasil em relação às naçôes modernas residia na capacidade plástica de unir os diversos. Com uma postura valorizadora do passado, das tradiçóes, no Manifesto Freyre chega até mesmo a elogiar o perfil mouro das ruas estreitas do Recife. Era preciso rejeitar certo modernismo ou ocidentalismo, que via em tudo que era antigo ou oriental um arcaísmo a ser abandonado (FREYRE, 2009 [1952], p. 7). O perfil oriental e mouro, presente nas tradiçôes culturais luso-brasileiras, deveria ser valorizado, e Freyre explicita isso especialmente em Sobrados e Mucambos (FREYRE, 1951 [1936]).

Duas tendências modernistas se antagonizaram no debate intelectual do Recife, uma articulada em torno do Diário de Pernambuco, ligada a Freyre e aos regionalistas, e outra organizada a partir do Jornal do Comércio, liderada por Joaquim Inojosa, de perfil mais afeito aos princípios da vertente modernista paulista. Enquanto Inojosa defende a demolição do passado rural e aristocrático, Freyre propóe a unidade nordestina a partir da valorização dos sentimentos, valores e da cultura construída sobre os alicerces senhoriais. Essa disputa se tornou acirrada a partir de 1925, com a publicação do Livro do Nordeste, e no ano seguinte, com o Congresso Regionalista. Dois anos depois, 
Freyre assumiu a chefia de gabinete do governador Estácio Coimbra, ligado às oligarquias rurais.

Gilberto Freyre apresenta um diagnóstico do Brasil e das relaçôes socioculturais do Nordeste a partir da descriçáo do panorama de construção e decadência do patriarcalismo das casas-grandes. O patriarcalismo perde centralidade em meio ao lento processo de dissolução da família tutelar. É também lenta a superaçáo dos valores senhoriais e tradicionais substituídos por novos, mais afeitos à esfera urbana, capitalista, classista. A exaltação do Nordeste em Freyre vem associada às aparentes soluçóes para as contradiçóes históricas, de forma a tornar a mudança reflexo de processos que se desenvolvem na longa duração, sem rupturas, sem insurreiçóes, marcados privilegiadamente pela forma pacífica, doce e flexível, tal qual o catolicismo e a família absorvente, tão característicos na obra do autor. A plasticidade, a miscigenação, a sexualidade aguçada pelo calor tropical se integram em suas obras em meio às compotas e quitutes característicos da mesa nordestina.

Nas receitas de Açúcar, Freyre (1997 [1939]) procura contribuir para a preservaçáo do patrimônio cultural que, segundo o autor, estaria ameaçado de se diluir em meio ao movimento avassalador da cultura de massas, de teor notadamente estrangeiro, que promovia a pasteurização cultural, inclusive no aspecto culinário.

É para o Nordeste da cana, de Pernambuco, que Freyre dirige seu olhar para analisar a cultura patriarcal da colônia. O próprio autor afirma que Casa Grande (FREYRE, 1989 [1933]) foi um trabalho de um "brasileiro do Nordeste no qual, $[\ldots]$ às bases germinalmente nordestinas, juntou-se a perspectiva amplamente universalista, e não apenas nacional. Esta, através da consideração em profundidade de condiçôes brasileiramente transnordestinas" (FREYRE, 1985 [1937], p. V.).

Em Nordeste (FREYRE, 1985 [1937]), descrevendo criticamente as mudanças impostas pela industrialização das usinas, com a urbanização e o capitalismo, que dissolvia as relaçóes pessoais enquanto as transformava em relaçóes de mercado, Freyre fazia o elogio ao cabra, ao pernambucano do ambiente rural. Se a civilização do açúcar fora marcada por "defeitos" persistentes na história brasileira, como a cultura hierárquica, avessa aos valores democráticos, a um maior equilíbrio da riqueza e dos bens, nenhuma outra seria "mais criadora do que ela de valores políticos, estéticos, intelectuais". 
O elogio ao ambiente senhorial nordestino não impede, entretanto, a descrição dos aspectos negativos, violentos e autoritários, que perpassam a história da dominação patriarcal e aristocrática de toda a região. Não obstante, Freyre não focaliza a pobreza ou a violência, ao contrário: preocupa-se com as expressôes de doçura e com o sentimentalismo construído nas relaçôes afetivas do Nordeste. Retrata o panorama de opulência, de onde surge como legenda a imagem impressionista do centauro, o senhor rural sobre seu cavalo, símbolo do poder aristocrático, ao lado do minotauro, o caboclo unido ao boi. A mitologia grega servia de parâmetro para a defesa da grandiosidade da civilização do açúcar.

Em Nordeste Freyre ressalva que seu olhar, assim como nas obras anteriores, é lançado apenas para um dos Nordestes, o da cana, o agrário, que contrastaria com outro, o dos sertôes, o pastoril. O Nordeste que Freyre destaca é aquele "que se alonga por terras de massapê e por várzeas, do Norte da Bahia ao Maranhão, sem nunca se afastar muito da costa" (FREYRE, 1985 [1937], p. XI), um ambiente de riqueza, de opulência, da grandiosidade dos tempos da glória patriarcal.

As obras contra as secas traziam a referência de um Nordeste desfigurado, dos sertóes, da areia, "de paisagens duras doendo nos olhos. Os mandacarus. Os bois e os cavalos angulosos [...] esse Nordeste de figuras de homens e bichos se alongando quase em figuras de El Greco..." (FREYRE, 1985 [1937], p. 5). O Nordeste que Freyre valoriza, ao contrário, é opulento, "de árvores gordas, de sombras profundas, de bois pachorrentos, de gente vagarosa e às vezes arredondada quase em sanchos-panças pelo mel de engenho", um Nordeste verde e cheio de água, onde a "terra gorda e de ar oleoso" se espraia (FREYRE, 1985 [1937], p. 5-6).

Segundo Freyre, o livro Nordeste tem um tom sentimental e impressionista, "em que estatísticas e números foram quase esquecidos para que as formas da região emergissem de seu passado turvo e de sua confusão atual, mais sentidas [...] que descritas e medidas..." (FREYRE, 1985 [1937], p. XVIII). Relendo Proust, a identidade nordestina derivaria de uma busca por um tempo perdido no passado rural e aristocrático da civilização da cana. Essa identidade regional seria construída a partir do século XVI, sob os domínios que dáo origem à casa-grande de pedra e cal (FREYRE, 1985 [1937], p. 7). Enquanto em Casa-grande e senzala e em Sobrados e Mucambos Freyre procura definir, 
a partir da família patriarcal, uma unidade cultural brasileira, em Nordeste as características regionais sobressaem.

O caráter exemplar da colonização do Nordeste se expunha na arquitetura miscigenada. Esta representaria um conjunto de misturas em comunhão e interdependência. Os laços de reciprocidade entre os diversos estratos da sociedade senhorial poderiam, assim, ser representados por essa arquitetura tipicamente brasileira, com influências indígenas, africanas e portuguesas, refletindo a miscigenação cultural que se verificaria no ambiente rural da colônia e que resguardaria, para Freyre, o fundamento da identidade brasileira.

Retomando um discurso ecológico que se assemelhava aos de José Bonifácio e de Joaquim Nabuco, Freyre denunciava o parasitismo do modelo de plantation, fundado no exclusivismo do latifúndio monocultor, na devastação pelo machado e pelo fogo. Animais e árvores haviam sucumbido para o avanço da cana e do gado. A área da vegetação original nordestina se configurava como um "náo lugar", por isso fora avassalada pela monocultura em meio a um "estado de guerra entre o homem e a mata".

A cana valorizou "o canavial e tornou desprezível a mata" (FREYRE, 1985 [1937], p. 65). Esse modelo de exploração destruiu o meio-ambiente, levando a alteraçôes climáticas significativas e intervenientes no regime de águas da regiáo (FREYRE, 1985 [1937], p. 46). O estado de guerra impediu o desenvolvimento de relaçóes líricas de proteção recíproca entre o homem e natureza, relações "não pervertidas pela monocultura furiosa" (FREYRE, 1985 [1937], p. 47).

Era preciso, segundo Freyre, revalorizar a ecologia nordestina, os seus rios, suas árvores, seus bichos, assim como suas gentes, os negros, os carroceiros, os jangadeiros, os canoeiros, os moleques, os senhores, as iaiás com os dentes podres de tanto comer doce, as senhoras que escondiam receitas de goiabadas deliciosas, etc. Gente miscigenada, forte e bela (FREYRE, 1985 [1937], p. 154), ao contrário do que diziam os nordestinos que haviam desvalorizado o Nordeste, associando-o ao atraso, à barbárie e à miscigenaçáo entendida como degeneraçáo, a exemplo de Morais Barros, Carneiro Leão, Nina Rodrigues, Sylvio Romero ou José Veríssimo, inspiradores de uma eugenia antinordestina que, mais tarde, seria reproduzida nos discursos de Oliveira Vianna. 
A cultura da cana aristocratizou o branco, tornando-o senhor, e degradou o índio e o negro, "primeiro em escravo, depois em pária", assim como também aristocratizou a casa de pedra e cal tornando-a casa-grande e degradou "a choça de palha em mucambo" (FREYRE, [1937] 1985, p.65). Na defesa do mucambo, o Manifesto Regionalista afirmava que ele "se harmoniza com o clima, com as águas, com as cores, com a natureza, com os coqueiros e as mangueiras, com os verdes e os azuis da regiáo como nenhuma outra construçáo" (FREYRE, 2009 [1952], p. 7); seria um valor regional, brasileiro, um valor dos trópicos pelo que representaria de harmonização estética e ecológica. $\mathrm{O}$ mal dos mucambos não estaria na qualidade da habitação, que seria às vezes melhor adaptada ao clima que muitas residências ricas, mas na localização em áreas degradadas.

Gilberto Freyre lamentava a degradação ambiental e também as mudanças promovidas pelo desenvolvimento industrial. As usinas haviam destruído as relaçóes próprias do ritmo patriarcal de outrora (PALLARES-BURKE, 2005, p. 235). Freyre dizia assistir ao "triste fim de uma aristocracia". O autor recusava o aburguesamento das relaçóes entre patrôes e empregados, pois eliminava a "subserviência filial" dos tempos senhoriais.

A valorização do passado senhorial como ambiente de formação da identidade mestiça é a chave para a formulaçáo de Casa-grande e senzala e para a indicaçáo de que essa identidade deveria ser valorizada como um passado que se projetaria no futuro, resguardando os elementos da cultura e das tradiçóes como veículos de afirmação da particularidade nacional criadora. O "espírito colonial" teria tido sua força interrompida, mas ainda seria uma fonte viva se valorizado como resultado da experiência histórica brasileira, contra os valores estrangeiros (PALLARES-BURKE, 2005, p. 236-237).

$\mathrm{Na}$ contramão da ordem senhorial e oligárquica, o governo de Getúlio Vargas deu início a um longo processo de afirmação do Estado Nacional em face do domínio secular dos senhores de terras nordestinos e das oligarquias estaduais. Esse processo foi marcado pela criação de políticas nacionais de desenvolvimento que dariam ensejo, nas décadas seguintes, às políticas de planejamento com vistas ao desenvolvimento do Nordeste. O nome que sobressairá nesse contexto é o de Celso Furtado. Enquanto Freyre elogiava o passado, o ambiente aristocrático, Furtado irá encontrar nesse passado a origem dos problemas do Nordeste. Seria preciso destruir as marcas persistentes da ordem 
senhorial, construída pelos séculos de escravidão e domínio latifundiário, para galgar o desenvolvimento econômico e social.

Nas décadas de 1950 e 1960, o tema do desenvolvimento do Nordeste vai se tornar central nos debates políticos, contribuindo inclusive para os eventos que precipitaram o golpe de 1964, que colocaria novamente Freyre e Furtado em campos opostos. Furtado constou da primeira lista de perseguidos pelo regime, lançada com o AI-1, enquanto Freyre foi um franco defensor da ditadura que se inaugurava naquele momento e amigo íntimo do general Castelo Branco. Dois nordestinos que representavam cada qual um Nordeste diferente. Freyre olhava para o Nordeste das árvores gordas, das elites nobres dos antepassados, Furtado se preocupava com o sertáo de onde proveio, do gado, dos mandacarus, das secas, dos trabalhadores sem-terra lutando contra o meio ambiente e a opressão das oligarquias rurais.

\section{Furtado e o desenvolvimento do Nordeste}

Gilberto Freyre teve de fugir do país em face da Revoluçáo de 1930, saiu do palácio do governo acompanhando Estácio Coimbra sob rajadas de balas (FREYRE, 1979, p. 12). Se, por um lado, os governos oligárquicos começaram a cair em meio ao fortalecimento do poder central, levando Freyre ao exílio, por outro, o novo Estado que se gestava com Getúlio viria a encampar o projeto de valorização das características regionais.

O regionalismo foi importante artifício para romper o localismo e o provincianismo estadual, característicos do sistema de reciprocidades de tipo coronelista vigente na I República, no qual o elo forte da cadeia de compromissos se fundava nos governos estaduais. Assim, o federalismo construído sob a política dos governadores de Campos Salles se rompia em favor da afirmaçáo do Estado Nacional, que forjava o povo e a naçáo a par da construçáo de identidades regionais. Daí a valorização de categorias como o nordestino, o gaúcho e o paulista, com identidades particulares integradas por meio do manto protetor e autoritário da Naçáo, corporificada na burocracia do Estado e na imagem personalista do líder, Getúlio Vargas.

Em 1938 Getúlio criou o Instituto Brasileiro de Geografia e Estatística (IBGE), no intuito de auxiliar no planejamento de políticas públicas setoriais e regionais que promovessem o desenvolvimento. Em 1942 o IBGE 
definiu, oficialmente, o quadro de divisão regional do país, dando origem às atuais cinco regiôes administrativas. Mais tarde, outras instituiçóes federais de circunscrição regional foram criadas, a exemplo do Banco do Nordeste, da Companhia Energética do Vale do São Francisco, assim como da SUDENE, agências regionais que consolidaram a definiçáo oficial do Nordeste como a regiâo composta por nove estados, da Bahia ao Maranhão.

Essa primeira onda desenvolvimentista durante o Estado Novo ajudou a fortalecer a categoria Nordeste por contraponto às demais regióes. O Nordeste era ainda associado ao sertão e continuava a ser entendido como um "vazio" territorial. A atenção para o Nordeste foi voltada, a partir dos anos 1940, para as políticas compensatórias do DNOCS e do Instituto de Açúcar e Álcool (OLIVEIRA, 2007, p. 2). Amparava-se a oligarquia rural tradicional da Zona da Mata e os latifundiários do interior, antes que o conjunto da sociedade, ampliando a concentraçáo da renda e vetando o acesso da maioria dos nordestinos a padróes de consumo e educaçáo minimamente compatíveis com aqueles professados nos estados do Sudeste e Sul do país.

Após a II Guerra e a onda keynesiana, articularam-se, a partir do final dos anos quarenta do século passado, novas vertentes desenvolvimentistas. Sob a direção de Raúl Prebisch, um conjunto de economistas e cientistas sociais latino-americanos se reuniram na Comissão Econômica para a América Latina (CEPAL), em Santiago do Chile, onde produziram novas teses sobre as perspectivas de desenvolvimento dos países subdesenvolvidos. $\mathrm{O}$ argumento da existência de relaçôes de vinculação hierárquica entre os países centrais e periféricos, que geravam relaçóes desiguais de troca, dando ensejo ao subdesenvolvimento, passou a influenciar o pensamento econômico nacional para se pensar o subdesenvolvimento do Brasil no âmbito internacional, em paralelo ao subdesenvolvimento do Nordeste no âmbito interno.

O subdesenvolvimento do Nordeste seria função do desenvolvimento dos estados do Centro-Sul. A concentração do dinamismo econômico nessa região reforçou a posição periférica do Nordeste.

A ampliação das desigualdades tornou a questão regional tema de importância central nos debates econômicos. Nesse contexto surgiram as primeiras propostas de planejamento com vistas ao enfrentamento da questão nordestina, superando o modelo de investimento em açóes focais que privilegiavam as 
elites, concentravam a renda e aprofundavam, com isso, o panorama de crise estrutural do Nordeste. Celso Furtado assumiria a frente de um conjunto de planos que viriam a forjar uma política planejada de desenvolvimento regional para o Nordeste, buscando inverter o padrão periférico de crescimento econômico com concentração da renda e da propriedade da terra.

Furtado provinha dos sertôes da Paraíba. Embora egresso de uma família de posses - seu pai era juiz e sua máe filha de fazendeiros -, vivenciara no sertão os flagelos das secas e das enchentes. Em suas memórias afirmava que sua infância fora "povoada de dificuldades, de amarguras", dizia: "Eu venho de um mundo que me parecia catastrófico. Pombal é das cidades mais ásperas do sertáo. Regiáo seca, de homens secos. Muito menino, eu olhava pela fresta da janela a chegada dos cangaceiros".

Aos 19 anos de idade, Furtado se mudou para a capital do estado, e no ano seguinte, em 1940, ingressou no curso de direito da UFRJ. Em 1946 iniciou o doutorado na Sorbonne, defendendo, dois anos depois, a tese intitulada Economia colonial no Brasil nos séculos XVI e XVII. Em 2000, quando finalmente a publicou, Furtado lembrava que a tese lhe servira como uma preparaçáo intelectual para construir uma ação concreta no sentido da transformação do país:

Precisávamos conhecer melhor nossa formação, os ingredientes de nossa cultura. Temos que reconhecer que a matriz patrimonial e escravista que está na base da formação do Brasil continua presente na configuração do povo brasileiro [...]. O estudo da economia brasileira veio a ser a primeira parte da reflexão mais abrangente que publiquei dez anos depois sob o título Formação Econômica do Brasil. (FURTADO, 2000 [1958], p. 6).

De volta ao Brasil, Furtado foi trabalhar como técnico do Departamento Administrativo do Serviço Público (DASP) e, em seguida, como economista da Fundação Getúlio Vargas, passando a ter contato com a temática do planejamento. Em 1949, quando Prebisch assumiu a direçáo da CEPAL, Furtado foi indicado como diretor da Divisão de Desenvolvimento do órgão da ONU. A CEPAL logo se tornaria o mais importante centro de pesquisa e reflexáo sobre o desenvolvimento da América Latina na década de 1950. Nesse período o economista acompanhou missóes em diversos países latino-americanos, e também visitou universidades nos Estados Unidos, o que foi importante para a definição de análises estruturais que empreenderia a seguir. 
Novamente de volta ao Brasil, em 1953 Celso Furtado participou da formação do grupo misto CEPAL-BNDE. O relatório final dos técnicos das duas instituiçóes auxiliaria, em 1955, a formulação do Plano de Metas de Juscelino Kubitschek.

Em 1957, Furtado se afastou temporariamente da CEPAL e passou a contribuir com o ISEB, proferindo um curso que depois seria compilado no livro Perspectivas da Economia Brasileira, no qual já prenunciava os argumentos que também serviriam de base para a formulação de seu mais famoso trabalho, o antológico Formação econômica do Brasil (FURTADO, 1963 [1957]), escrito no mesmo ano, quando o autor fez seu pós-doutoramento no King's College de Cambridge.

Furtado associava a formação econômica do Nordeste no século XX aos efeitos do modelo colonial que entrara em lenta decadência a partir do século XVII. Tanto a agricultura quanto a pecuária da regiáo teriam verificado um crescimento de "caráter puramente extensivo, mediante a incorporação de terra e máo de obra, náo implicando em transformaçóes estruturais que repercutissem nos custos de produção e portanto na produtividade" (FURTADO, [1957] 1963, p. 77). As crises no mercado de açúcar se refletiam em migração para o interior, aumentando os braços para a economia do gado, assim como também se ampliava a cultura de subsistência. Com o tempo, a economia de subsistência aumentou - por um lado, pela crise da economia açucareira, com rendas decrescentes em face da não incorporaçáo de mecanismos de aumento de produtividade e dinamismo; e por outro, pelo fato de que a produtividade do setor pecuário diminuía de acordo com o crescimento da máo de obra. Progressivamente, grande parte dos nordestinos passaram a produzir apenas o necessário para a sobrevivência, verificando-se "uma involução nas formas de divisão do trabalho e especialização” (FURTADO, 1963 [1957], p. 82). A estagnação do Nordeste só poderia ser superada por meio de uma mudança estrutural promovida através de mecanismos de planejamento e intervenção estatal, mas, para tanto, seria preciso romper a forte barreira dos interesses das elites oligárquicas.

Celso Furtado se desligou definitivamente da CEPAL em 1958 e assumiu uma diretoria no Banco Nacional de Desenvolvimento (BNDE), onde passaria a sistematizar um plano de intervenção para o desenvolvimento do Nordeste. Em A fantasia desfeita, Furtado afirma que renunciara ao cargo da 
Os Nordestes de Freyre e Furtado | José Henrique Artigas de Godoy

ONU e aceitara o do banco apenas sob uma condição: sua "atuação se circunscreveria à área do Nordeste" (FURTADO, 1989, p. 37).

Logo após sua chegada ao BNDE, Furtado se tornou interventor em um dos grupos criados pelo banco com a função de assessoria técnica, o Grupo de Trabalho para o Desenvolvimento do Nordeste (GTDN). Nesse mesmo período, em meio à seca de 1958, uma das mais graves do século, JK decidiu dar mais atenção à questão nordestina e vinculou o GTDN diretamente à presidência da República, tornando-o seu principal órgão assessor.

Crítico do modelo de política executada para o semiárido, Furtado se mostrava descrente do governo de Juscelino, que produzia enormes dívidas com a construção de Brasília, um investimento improdutivo, enquanto tendia a reproduzir a estratégia da "solução hidráulica" para o Nordeste, criando a maior de todas as barragens da época, a de Orós, que agregou à regiáo mais três bilhôes de metros cúbicos de água represada.

Alguns estudiosos já vinham fazendo pesquisas sistemáticas sobre a ecologia da região semiárida. José Guimarães Duque demonstrava, em suas críticas às açôes de açudagem do DNOCS, que faltava relacionar a ecologia com as estruturas socioeconômicas, o que permitiria perceber que o fenômeno da "seca" é em grande parte devido a essas estruturas. Sem modificá-las, toda tentativa para solucionar o referido problema careceria de seriedade. Também faltava compreender as peculiaridades das relaçóes da regiáo com o polo industrial emergente no Centro-Sul do país (FURTADO, 1989, p. 39).

De acordo com a vertente cepalina, a estrutura do subdesenvolvimento refletia a associação entre estruturas arcaicas e modernas que, articuladas, reproduziam as desigualdades e obstavam o desenvolvimento na periferia. Os dois Brasis, como destacavam L'Ambert e Bastide, representariam, na vertente cepalina de Furtado, o paralelismo entre estruturas arcaicas no Nordeste e modernas no Centro-Sul. O subdesenvolvimento de uma região era função do desenvolvimento de outra, amplificando as desigualdades regionais e as relações de subordinação.

Viajando por todo o Nordeste em 1958, Celso Furtado verificava que a condição da população trabalhadora rural era de calamidade. Não fosse a ação do governo federal, parte dela seria dizimada pela fome ou migraria. Essa populaçáo miserável era mantida sob dependência dos grandes fazendeiros, que a transformava em "curral eleitoral". 
Furtado verificava que o problema maior do Nordeste era de ordem alimentar. Especialmente após a construção, pelo DNOCS, de açudes e barragens nas grandes fazendas, o gado e o algodão, resistentes, não sofriam tanto os efeitos das estiagens. Por outro lado, os trabalhadores rurais, em anos de chuvas regulares, produziam seus alimentos normalmente, mas nas estiagens ficavam sem os meios de subsistência, tornando-se suscetíveis à política coronelista de proteção e dependência. "Em síntese, a ação do governo, sob controle da classe latifundiária, reforçava as estruturas existentes e agravava os efeitos sociais da seca" (FURTADO, 1989, p. 39). Um dos meios de reduzir os efeitos dessa situação passava por uma política de estímulo à irrigação para a agricultura familiar.

A criação de vias de comunicação rodoviária entre o Nordeste e o Centro-Sul do país aumentava o panorama desolador da regiáo, pois obstava ainda mais a consolidação de um setor industrial autônomo que produzisse emprego e renda e estimulasse o mercado interno na região, retendo capital para investimento produtivo.

Pressionado pela oposição, pelo movimento social, pela Igreja e pelos militares, JK decidiu tomar uma ação enérgica em relação ao Nordeste. Ele se ressentia de ter investido mais que qualquer outro em obras contra as secas e amparo aos flagelados por meio de frentes de trabalho e, mesmo assim, continuar a ser criticado por todos os grupos quando se tratava de sua política regional de desenvolvimento. Nesse contexto de tensão, Furtado apresentou seu diagnóstico e sua proposta para o Nordeste. Em primeiro lugar, criticou claramente a continuidade com a política do passado que havia se mostrado incapaz de enfrentar o problema social do Nordeste e, ao contrário, ampliava a estrutura de dominação e de dependência que inibia qualquer iniciativa de desenvolvimento autônomo. Em segundo lugar, era preciso uma política global de desenvolvimento para o Nordeste que superasse as iniciativas focais e desconexas, uma política que suplantasse as particularidades estaduais em favor do interesse regional, uma política orquestrada pelo governo federal em associação com os governadores.

O subsídio aos produtores de cana e a política de açudagem para patrocinar a pecuária extensiva vetava a possibilidade de desenvolvimento de um setor agrícola produtor de alimentos, obrigando a importação de produtos do Centro-Sul, o que aprofundava o panorama de dependência e drenagem de 
capitais. Era fundamental uma política de irrigação que promovesse a agricultura para a produção de alimentos. Para tanto, seria preciso promover uma profunda guinada na política, levada a cabo pelo governo, que deixaria de combater a seca e passaria a procurar conviver da melhor forma possível com ela, promovendo a agropecuária de acordo com os potenciais e a ecologia da região. Os programas de estímulo à produção de alimentos deveriam ser implantados não apenas no semiárido, mas também na Zona da Mata, dominada pela monocultura canavieira.

Furtado era taxativo: náo era a seca o problema do Nordeste, mas o latifúndio. A concentração da propriedade fundiária e da renda, dos recursos naturais e infraestruturais é que produzia o flagelo da seca. O flagelo tinha origem social e não ambiental.

A reorientação das políticas para o Nordeste deveria criar as bases para a industrialização local, tendendo a empregar na regiáo os capitais produzidos e retidos por meio do consumo e da circulaçáo no mercado regional. A industrialização estimularia a formação de uma nova classe dirigente nordestina, burguesa e desconectada das tradiçóes oligárquicas, um grupo de empreendedores que pudesse assumir a frente de investimentos industriais, criando um novo ciclo econômico virtuoso no Nordeste.

Depois que Furtado apresentou a sua proposta a JK, o presidente imediatamente deu encaminhamento ao conjunto de programas que seriam, a partir daquele momento, denominados de Operação Nordeste, e fechou a reunião dizendo que a partir daquele momento o Nordeste seria em seu governo táo prioritário quanto a construção de Brasília (FURTADO, 1989, p. 45).

Nessa época Antonio Callado denunciava, em sua coluna no Correio da Manhã, o favorecimento das elites agrárias do Nordeste por meio de políticas de combate aos efeitos das secas. Denominava o movimento dos fazendeiros da região, em associação com órgãos governamentais como o DNOCS, como "indústria da seca". Os industriais da seca se valeriam de renúncias fiscais, de estímulos diretos, da compensação de dívidas e do crédito governamental, usando a imagem depauperada dos nordestinos para vincular verbas à construção de obras de interesse particular dos grandes proprietários do semiárido. Os trabalhadores submetidos ao flagelo das secas eram empregados temporariamente em grandes frentes de trabalho para a construçáo de açudes, barragens e canais que, comumente, localizavam-se em áreas das grandes fazendas, 
fortalecendo o poder econômico e a dominação política local. Esses açudes e canais não eram produzidos para promover irrigação ou produzir energia, serviam apenas para amparar, nos períodos de estiagens, a pecuária extensiva das grandes propriedades, alheando a maioria da população dos sertóes do acesso à água. A "solução hidráulica" apresentada pelo DNOCS envolvia a construção de centenas de açudes e barragens que tinham parte substancial da água perdida por evaporação. O Nordeste em 1958 possuía sete bilhôes de metros cúbicos de água represada, sem que, por sua vez, essa água promovesse a melhoria da qualidade de vida da populaçáo local ou a ampliação das oportunidades econômicas por meio do uso produtivo da infraestrutura construída pelo governo. O problema é que a água não era para todos, mas apenas para os grandes proprietários, que se beneficiavam econômica e politicamente do panorama de desamparo da população nordestina.

Antes mesmo que fosse formulada uma proposta final de intervenção, o Correio da Manhã já noticiava a intenção de se criar uma política global para o Nordeste, rompendo com o tradicional estímulo à "indústria da seca". As matérias sucessivas do jornal ajudaram a criar um clima de mudança no governo e na sociedade. As elites políticas nordestinas, em polvorosa, se agitavam, enquanto Dom Helder Câmara apresentava a Furtado o auxílio da CNBB ao projeto de reformas: "você vai necessitar de apoios nessa luta contra privilégios e abusos de poder. Pode contar comigo sem reservas" (FURTADO, 1989, p. 47).

O GTDN produziu um estudo intitulado Uma politica de desenvolvimento para o Nordeste, escrito por Furtado, mas publicado como produção coletiva, que viria a servir de baluarte para a Operação Nordeste. O estudo afirmava, em primeiro plano e com um conjunto de dados estatísticos, a existência de brutais desigualdades econômicas e sociais entre o Nordeste e o Centro-Sul do país. Em 1959 foi criado o Conselho de Desenvolvimento do Nordeste (CODENO), como forma de resolver questóes federativas envolvidas com os projetos de intervenção no Nordeste, evitando que o regionalismo estadualista comprometesse o programa de mudanças.

Verificava-se que um terço dos nordestinos estavam desempregados, por isso a política industrial proposta promoveria o emprego, estimularia a criação de um grupo de investidores privados, uma nova classe dirigente "imbuída do espírito de desenvolvimento" que supostamente fixaria capitais até então drenados para os polos dinâmicos da economia brasileira - no Centro-Sul. 
Além da política industrial, da política agrícola, que previa a produção de alimentos no sertão e no litoral e o aumento da produtividade, também se incluía no programa de reformas o estímulo à migração para a fronteira maranhense, para onde se deslocaram milhares de cearenses.

A Operação Nordeste serviria para enterrar, temporariamente, "as falácias que secularmente serviram para justificar a utilização de dinheiro público na perpetuação de estruturas anacrônicas e anti-sociais" (FURTADO, 1989, p. 56).

A intervenção política e econômica no Nordeste exigia a criação de uma instituição executiva que fosse independente daqueles órgãos governamentais marcados por vícios do passado, por isso foi proposta a criaçáo da Superintendência para o Desenvolvimento do Nordeste (SUDENE), que gerou conflitos com as oligarquias agrárias nordestinas, as quais viam na instituição uma arma contra o latifúndio e os históricos privilégios das elites rurais da regiáo. Políticos tradicionais e fazendeiros temiam a perda do controle sobre os currais eleitorais. A SUDENE se estruturou como um órgáo transparente, que contava com a participação dos nove governadores da regiăo, de diferentes partidos, o que eliminava a possibilidade de favorecimento e rompia com os princípios corruptos da burocracia dos outros órgáos. $\mathrm{O}$ critério suprapartidário da SUDENE era absolutamente fundamental, sem o qual não seria possível vislumbrar apoio dos governadores de forma a viabilizar as obras de infraestrutura essenciais para a Operação Nordeste.

Furtado teve papel central na definição dos marcos do debate sobre o planejamento econômico do governo JK. Criticou a proposta de política industrial, comercial e cambial, na contramáo da avaliaçáo da maioria dos formuladores do plano de desenvolvimento. Dizia que elas favoreciam o polo dinâmico da economia mas, por outro lado, produziam resultados trágicos no Nordeste (BACELAR, 1996, p. 75).

Após uma trajetória marcada por dificuldades técnicas, burocráticas e, principalmente, políticas, embora a SUDENE tenha desempenhado um papel-chave para a reflexão sobre o Nordeste e para a elaboração de estratégias de desenvolvimento e planejamento, patinou na execuçáo de políticas que produzissem resultados significativos. Apesar de Furtado ter ficado na SUDENE na gestão de Jânio, a mudança do perfil do novo governo demonstrou a falta de comprometimento com mecanismos regulares de financiamento 
que permitissem a autonomia executiva do órgão, que foi perdendo poder de intervenção.

Após a atribulada transição para o governo João Goulart, Furtado foi indicado para o recém-fundado Ministério do Planejamento, que deu início a uma nova referência na formulação de políticas públicas no Brasil. A ideia desenvolvimentista, baseada no princípio do planejamento, se tornava vitoriosa, mas a política para o Nordeste ainda carecia de efetividade e eficácia. Furtado elaborou o plano trienal e, mais tarde, voltou à direção da SUDENE, estimulando subsídios e investimentos no sentido de favorecer a instalação de indústrias no Nordeste.

Com o Golpe Militar, a onda desenvolvimentista - iniciada nos anos cinquenta e aprofundada na década seguinte, que havia dado espaço para a definição de políticas de planejamento para o Nordeste - teve seu fim decretado. Furtado foi exilado sob a acusação de corromper a juventude.

Em 1982, Furtado voltaria a cerrar críticas ao modelo de desenvolvimento promovido pelos militares, que vinha reproduzindo a concentração regional da renda e a dependência do Nordeste em relação às indústrias do Centro-Sul. Ao lado da defesa da redemocratizaçáo, Furtado denunciava que a concentração regional da riqueza continuava a grassar no país. Criticando a importação de modelos de desenvolvimento exógenos e inadequados à realidade do Brasil, afirmava que tínhamos de evitar o erro de empreender uma modernização mimética, que privaria os brasileiros da identidade cultural, um modelo modernizador que só vinha criando desigualdades sociais e regionais (FURTADO, 1982, p. 137).

Ora, se é verdade que houve melhora considerável da infraestrutura física, particularmente nos setores de transportes e energia, não é menos evidente que os salários reais da grande massa da população em nada refletiu [sic] esse crescimento econômico, e que a grande maioria da população rural pouco ou nada dele se beneficiou. É verdade que a classe média, antes raquítica na região, passou a ocupar um espaço importante. Em compensação, a taxa de subemprego invisível (pessoas ganhando até um salário mínimo na ocupação principal) se mantinha em 80 por cento em 1979. A emergência de uma classe média afluente, em meio à pobreza absoluta da maioria da população, é a evidência maior do malogro da política de desenvolvimento seguida na região. (FURTADO, 1989 [1984], p. 5-6).

Furtado reconhecia que o governo era fortemente influenciado pelos interesses das regiôes em que se concentrava o poder econômico. A SUDENE, 
como tinha sido originalmente concebida, deveria servir de contrapeso a essa influência. Como o Nordeste não detinha poder econômico, procurava-se valorizar o seu peso político. O peso político do Nordeste, entretanto, diminuía em meio ao processo de centralizaçáo do governo militar, que eliminou o poder dos estados e das regióes. Por isso a SUDENE havia se descaracterizado e deixado de agir no sentido da ruptura com o domínio econômico incontrastado do Centro-Sul e da oligarquia latifundiária nordestina (FURTADO, 1986).

\section{O passado e o futuro do Nordeste}

O acompanhamento da trajetória e do pensamento de Freyre e Furtado permite perceber aproximaçóes e distanciamentos entre duas clássicas abordagens acerca do Nordeste. De forma geral, há uma relativa aproximação entre seus diagnósticos sobre a decadência econômica e social do Nordeste. Já no tangente às prescriçóes para o desenvolvimento da regiáo, percebem-se principalmente antagonismos.

Freyre e Furtado elencam um conjunto de fatores sociais, econômicos, políticos, culturais e ecológicos que influenciaram na decadência da regiáo e sua crescente dependência em relação ao Centro-Sul. É possível traçar um perfil genérico dos elementos principais que teriam interferido para que o Nordeste perdesse a posição hegemônica do passado e passasse a concentrar pobreza e miséria.

A economia e a sociedade nordestinas tiveram seus fundamentos na cultura da cana no litoral. A monocultura exigiu a criaçáo de uma economia subsidiária produtora de alimentos no agreste, que mais tarde entraria pelos sertôes com o avanço da pecuária e, em seguida, do algodão.

O modelo de exploraçáo canavieiro e monocultor foi profundamente degradante do meio ambiente, destruiu a mata e a fauna e poluiu os rios. $\mathrm{O}$ machado e o fogo foram implacáveis, acabando com parte significativa do patrimônio natural do Nordeste.

O império do latifúndio foi conservador, não incorporou inovaçôes, mudanças que modernizassem ou industrializassem as atividades agrícolas e pastoris. O latifúndio teve a funçáo de manter a ordem senhorial e a dominaçáo política oligárquica e coronelista antes que de produzir capital e acumulaçáo. 
A concentração da propriedade fundiária seria o fundamento das desigualdades e perpetuaria o padrão de dominaçáo exercido pelos grandes proprietários. A dominação senhorial e patriarcal escravista foi substituída por relaçôes de dependência, criando, por meio da meação, da parceria e do aforamento, formas de reprodução da hierarquia social e da miséria dos trabalhadores.

Como não houve modernização e industrialização do campo que promovesse aumento de produtividade, a economia do açúcar gerou um padráo decrescente de acumulaçáo. Essa acumulaçáo, entretanto, não se transformou em poupança que promovesse inversóes produtivas, mas verteu-se, prioritariamente, para o consumo das elites rurais aristocráticas, impedindo qualquer ganho de competitividade. Esse padrão, que promoveu a dependência de produtos de outras regióes e países, acirrou o perfil subdesenvolvido do Nordeste. A drenagem de recursos do Nordeste para o Centro-Sul barrou as chances de integração nacional.

A dependência e a estagnação da economia nordestina, assim como seus rendimentos decrescentes, levaram a uma intensificação da exploraçáo da mão de obra como único recurso de concentração de renda para manter o padrão aristocrático de consumo, incompatível com a realidade econômica regional.

Por sua vez, a decadência política, social e econômica do Nordeste influenciou na desvalorização das tradiçôes culturais gestadas no mundo rural, tendendo a uma pasteurizaçáo cultural, característica da sociedade de massas e da modernização marcada pelo imperialismo. A cultura popular do Nordeste teria sido deixada de lado em favor de valores e referenciais culturais exógenos.

Esse conjunto de fatores coligados teriam impedido a formação de um campesinato que promovesse a redução dos laços de dependência por meio da produção de alimentos em pequenas e médias propriedades, o que tendencialmente poderia representar estímulo à independência dos trabalhadores em relação às elites rurais e incentivo à criação de um mercado interno regional, promovendo dinamismo suficiente para o investimento industrial.

O padrão de desenvolvimento humano e material do Nordeste após a abolição não teria sido alterado em sua substância. Os homens-livres na ordem escravocrata e pós-escravocrata haviam se tornado trabalhadores dependentes e politicamente submissos, desprovidos dos direitos de cidadania, o que vetou 
Os Nordestes de Freyre e Furtado | José Henrique Artigas de Godoy

o fortalecimento da democracia na regiáo, permitindo, em contrapartida, a continuidade da política oligárquica.

Para Freyre e Furtado, haveria pelo menos dois Nordestes, o do litoral e o do sertão. Haveria uma relação de dependência e integração entre as regióes, relegando principalmente aos trabalhadores do sertáo as maiores carências (CALAZANS, 2007).

O flagelo das secas não era causado pelas estiagens, mas pela concentração da terra, da renda, do crédito, dos investimentos em infraestrutura e, principalmente, da água. A relaçáo de controle dos grandes fazendeiros sobre os recursos naturais e sobre as obras contra as estiagens tendia a reproduzir o coronelismo e a indústria da seca.

Se o diagnóstico acerca da história de entraves ao desenvolvimento do Nordeste é em muitos aspectos comum a Freyre e Furtado, suas prescriçôes para a solução do problema regional são em, alguns aspectos, semelhantes e, em outros, antagônicas.

Freyre encontra no engenho patriarcal nordestino o ambiente de convívio solidário, de miscigenação e comunhão, de antagonismos em equilíbrio, onde repousariam os laços mais profundos da cultura nobre e do caráter social brasileiro. O equilíbrio dos antagonismos permite a Freyre compatibilizar sua crítica à decadência econômica do Nordeste com a defesa das tradiçôes. Assim, à destruição da mata se contrapóe o efeito criador promovido pela cana. Se as relações sociais são hierárquicas, a miscigenação reduz as distâncias sociais, se há violência, o açúcar adocica os comportamentos, aproximando os desiguais, afirmando identidades compartilhadas. À violência da escravidão se contrapóe a doçura fraternal dos escravos domésticos.

O elogio ao mundo rural se apresenta em Freyre por meio da exaltação da cultura dos engenhos, do passado nobre das elites nordestinas, da "açucarocracia” pernambucana, como classifica Evaldo Cabral de Mello. Exaltar o passado do Nordeste do açúcar não significava saudosismo anacrônico e reacionário, mas a defesa de um futuro de acordo com as tradiçóes e não contra elas. Freyre defendia uma outra modernidade, nem ocidental nem oriental, uma modernidade nacional que exprimisse valores cosmopolitas sem, contudo, deixar de destacar as particularidades regionais, os costumes e a cultura nordestina, gestada nos domínios da cana. Ricardo Benzaquen de Araújo afirma que a 
modernidade de Freyre seria "alternativa, polifônica e nada estetizante, capaz de aliar a degustaçáo de iguarias estrangeiras com o consumo da comida regional" (ARAÚJO, 2005).

Furtado, por sua vez, vê no latifúndio e na dependência do trabalhador livre entraves incontornáveis ao desenvolvimento. A primeira e mais importante tarefa a ser realizada no país seria a da reforma agrária, a "democracia rural", como em Rebouças e Nabuco, que pudesse garantir os meios de independência que promovessem a cidadania dos trabalhadores. A concentração da terra e da renda se vinculava historicamente aos princípios da escravidão que, mesmo com a abolição, não foram superados. O Nordeste seria resultante da "obra da escravidão" de que falava Joaquim Nabuco, da não integração social dos trabalhadores que, dissociados do direito à propriedade, mantiveram-se, e em grande medida mantém-se até hoje, subalternizados no campo e nas cidades do Nordeste.

Nenhuma nação moderna poderia conviver com as desigualdades sociais brutais como as existentes no Brasile, especialmente, no Nordeste. Para Furtado, era preciso uma intervenção estatal para que se garantisse terra, apoio técnico e crédito para estimular a agricultura familiar na regiáo. Essa agricultura policultora deveria ser irrigada, produzindo alimentos em pequenas e médias propriedades, de forma a reduzir a dependência regional, fomentar o mercado interno local e regional e a poupança, que poderia refletir em investimento industrial via substituiçáo das importaçôes de mercadorias provenientes do Centro-Sul do país. $\mathrm{O}$ apoio estatal para planejar e financiar os investimentos seria fundamental para romper com o parasitismo das elites oligárquicas.

Freyre e Furtado foram defensores de um desenvolvimento ambientalmente sustentável. Freyre, em particular, foi um grande estimulador dos estudos ecológicos do Nordeste, procurou inventariar a fauna e a flora como uma forma de indicar que o futuro do país residiria na valorização da riqueza do patrimônio natural e cultural do Brasil e do Nordeste. Furtado também defendia a preservação do patrimônio natural e cultural do país, em seus estudos econômicos são patentes a defesa da preservação ambiental e a crítica aos desmatamentos que deram lugar à cana. Como Ministro da Cultura, embora sob severas limitaçôes políticas e financeiras, Furtado procurou manter seus ideais nacionalistas e regionalistas, valorizando as particularidades culturais do Brasil e do Nordeste. O subdesenvolvimento não era apenas uma faceta 
Os Nordestes de Freyre e Furtado | José Henrique Artigas de Godoy

econômica, ele se expressava também no aspecto cultural, por isso era preciso investir na valorização e no estímulo à produçáo e ao patrimônio cultural do país e da região.

Furtado propunha transformaçóes radicais, como na acepção de Antonio Candido (1988), envolvendo a defesa de mudanças profundas, embora dentro da ordem estabelecida, uma concepção não revolucionária, como nas teses de Nabuco, Manoel Bomfim e Sérgio Buarque de Holanda. Freyre não. Ele foi um conservador. Encontrava os elementos do futuro no passado e na conservação. Se os autores propóem uma via particular de modernização, a de Freyre é voltada para os tempos senhoriais dos ioiôs e das iaiás. Furtado, por sua vez, jamais nutriu qualquer valor afeito ao mundo aristocrático e senhorial - ao contrário, queria acabar com seus resquícios no Nordeste. Do ponto de vista prescritivo, Furtado tinha um olhar voltado para o futuro, para o desenvolvimento capitalista, que seria antagônico às estruturas sociais, políticas e econômicas do passado nordestino.

Homem do litoral, sede maior dos domínios da cana, Freyre lança um olhar para o Brasil partido da Zona da Mata. Furtado, ao contrário, foi sempre um homem do sertáo, que olhou para o sertáo e o sertanejo. Do amálgama entre o Nordeste do litoral e o Nordeste do sertão emergem outros Nordestes, ainda mais profundos: o do senhor e o do escravo, do rico e do pobre, do fazendeiro e do sem-terra. Intelectuais e militantes engajados, esses dois nordestinos ajudaram a escrever a história do pensamento social brasileiro e a criar uma identidade do Nordeste e dos nordestinos.

\section{Referências}

ALBUQUERQUE JR., D. M.. A invenção do Nordeste e outras artes. 4. ed. São Paulo: Cortez, 2009 [1994].

ARAÚJO, R. B. de. Guerra e Paz: Casa-grande e senzala e a obra de Gilberto Freyre nos anos 30. 2. Ed. São Paulo: Ed. 34, 2005 [1994].

BACELAR, T. A "questão regional" e a "questão nordestina". In: TAVARES, Maria da Conceição (Org.). Celso Furtado e o Brasil. São Paulo: Fundação Perseu Abramo, 1996. p. 71-92.

CALAZANS, R. Ambivalências: o Nordeste nas obras de Gilberto Freyre e Celso Furtado. Revista Brasileira de Ciências Sociais, São Paulo, v. 22, n. 64, p.75-80, 2007. 
CANDIDO, A. Radicalismos. Revista de Estudos Avançados/USP, São Paulo, v.4, n.8, p.4-18, abr. 1990.

CANO, W. Celso Furtado e a questão regional no Brasil. In: TAVARES, Maria da Conceição (Org.). Celso Furtado e o Brasil. São Paulo: Fundaçấo Perseu Abramo, 1996. p. 93-121.

CARVAlHO, R. E. Ismael de. A invenção do Nordeste na obra de Gilberto Freyre e de Celso Furtado. Trabalho apresentado ao XII Encontro Regional de História da ANPUH, 2006. Anais... Rio de Janeiro, ANPUH, 2006.

CORREIA DE ANDRADE, M. Gilberto Freyre e os grandes desafios do século XX. Petrópolis: Vozes, 2002.

DUARTE, R. H. "Com açúcar, com afeto": impressôes do Brasil em Nordeste de Gilberto Freyre. Revista Tempo, Rio de Janeiro, v.10, n. 19, p. 125-147, 2004.

FALAS do trono. Brasiliense, São Paulo, 1977. [IMPÉRIO]

FREYRE, G. Casa-grande e senzala. 26. ed. Rio de Janeiro: Record, 1989 [1933].

Sobrados e mucambos: decadência do patriarcado rural e desenvolvimento do urbano. 2. ed. Rio de Janeiro: José Olympio, 1951 [1936]. 3 v.

Nordeste. 5. ed. Recife/Rio de Janeiro: José Olympio/FUNDARPE, 1985 [1937].

Açúcar. São Paulo: Cia. das Letras, 1997 [1939].

Manifesto Regionalista. [1952] Disponível em: <www.arq.ufsc.br/arq5652/ modulo2modernidade/manifestos/manifestoregionalista.htm >. Acesso em: 4 set. 2010.

Pessoas, coisas e animais. São Paulo: MPM propaganda, 1979.

FURTADO, C. Economia colonial no Brasil nos séculos XVI e XVII. São Paulo: Hucitec/ ABPHE, 2001 [1948].

Formaçáo econômica do Brasil. Brasília: Ed.UnB, 1963 [1957].

O mito do desenvolvimento econômico. Rio de Janeiro: Paz e Terra, 1974.

. A nova dependência: dívida externa e monetarismo. 2. ed. Rio de Janeiro: Paz e Terra, 1982.

O Nordeste: reflexôes sobre uma política alternativa de desenvolvimento. Mossoró: ESAM, 1989 [1984]. Coleção Mossoroense, série B, n. 649.

A fantasia desfeita. 3. ed. Rio de Janeiro: Paz e Terra, 1989.

FURTADO, C.; MOLION, L. C. B.; AB'SABER, Aziz Nacib. Nordeste: o tempo perdido. Recife: ASA Pernambuco, 1986. 
Os Nordestes de Freyre e Furtado | José Henrique Artigas de Godoy

GIUCCI, G.; LARRETA, Enrique Rodríguez. Gilberto Freyre: uma biografia cultural. Rio de Janeiro: Civilização Brasileira, 2007.

OLIVEIRA, L. L. A invenção do Nordeste e do nordestino: roteiro de pesquisa. Trabalho apresentado ao XIII Congresso Brasileiro de Sociologia, 2007. Anais... Recife: UFPE, 2007. Disponível em: <http://virtualbib.fgv.br/dspace/handle/10438/6649 >. Acesso em: 15 ago. 2010.

Recebido em: 20.03.2012

Aprovado em: 25.04.2013

\section{The Northeasts from Freyre and Furtado}

\section{Abstract}

The article seeks to relate two classical interpretations of the economic and social thinking of Brazil and th Northeast made by Gilberto Freyre and Celso Furtado. Freyre was the one responsible for defining the category Northeast references from not only natural, but also social, economic, political and cultural. Furtado, in turn, was tehe most prominent intellectual to defend regional public policy for the Northeast, highligghting the particular characteristics that shaped the political, social, economic and cultural regional subordination for the Center-South. With very different life paths, Freyre and Furtado expose disparate portraits of Brazil and the Northeast. Wrote under various circunstances and analytical references, however, present innovative approaches that approach in the search for a totalizing explanation of the Brazil, the Northeast and the people of Northeast.

Keywords: Gilberto Freyre. Celso Furtado. Northeast. 